\title{
Loss of expression for the Wnt pathway components adenomatous polyposis coli and glycogen synthase kinase 3- $\beta$ in parathyroid carcinomas
}

\author{
C. CHRISTOFER JUHLIN ${ }^{1,2}$, FELIX HAGLUND ${ }^{1}$, ANDREA VILLABLANCA ${ }^{1,2}$, LARS FORSBERG $^{1}$ \\ KERSTIN SANDELIN ${ }^{1}$, ROBERT BRÄNSTRÖM ${ }^{1}$, CATHARINA LARSSON $^{1}$ and ANDERS HÖÖG ${ }^{2}$ \\ Departments of ${ }^{1}$ Molecular Medicine and Surgery and ${ }^{2}$ Oncology-Pathology, Karolinska Institutet, \\ Karolinska University Hospital Solna, CMM L8:01, SE-171 76 Stockholm, Sweden
}

Received August 20, 2008; Accepted October 16, 2008

DOI: 10.3892/ijo_00000173

\begin{abstract}
The development of parathyroid carcinoma has been associated with inactivating mutations of the Hyperparathyroidism type 2 (HRPT2) gene encoding parafibromin, a member of the human RNA Polymerase II-Associated Factor Complex (hPAF) and functionally linked to the Wingless type (Wnt) pathway. In this study, we characterized the expression of Wnt pathway molecules in parathyroid benign and malignant tumors. Tumors were investigated by immunohistochemistry supplemented with Western blot analyses using monoclonal antibodies. The study comprised 13 tumors from 12 cases of unequivocal parathyroid carcinoma, 18 cases of parathyroid adenoma, as well as nontumorous parathyroid tissue. Adenomatous polyposis coli (APC) was uniformly expressed in non-tumorous parathyroid tissue and adenomas, but absent in carcinomas from 9 of 12 patients $(75 \%)$. Expression of glycogen synthase kinase 3- $\beta$ (GSK3- $\beta$ ) was lost in $4 / 12$ carcinomas and in $1 / 18$ adenomas. The loss of APC and GSK3- $\beta$ did not lead to augmentation of the Wnt target protein cyclin D1 or the Wnt oncoprotein B-catenin. Active B-catenin showed cytoplasmic and nuclear expression in all non-tumorous tissues and tumors. Loss of APC immunoreactivity was significantly associated with parathyroid carcinoma as compared to adenomas $(\mathrm{p}<0.001)$, giving a high specificity $(100 \%)$ and sensitivity $(75 \%)$ for the detection of parathyroid malignancy. The results suggest the involvement of Wnt-pathway members APC and GSK3-B in parathyroid carcinoma development. In addition, APC immunohistochemistry could become a useful tool for improved recognition of parathyroid carci-
\end{abstract}

Correspondence to: Professor Catharina Larsson, Department of Molecular Medicine and Surgery, Karolinska Institutet, Karolinska University Hospital Solna, CMM L8:01, SE-171 76 Stockholm, Sweden

E-mail: catharina.larsson@ki.se

Key words: APC expression, GSK3- $\beta$, parathyroid carcinoma, B-catenin, cyclin D1 noma together with immunohistochemistry for parafibromin and proliferation index. Furthermore, the involvement of APC related pathways in the disease development opens possibilities to explore therapeutic routes complementary to surgery.

\section{Introduction}

Parathyroid carcinoma is a highly aggressive form of primary hyperparathyroidism (PHPT). Typical findings are very high levels of serum calcium with severe accompanying symptoms. Recurrent and/or metastatic disease and/or histopathological evidence of infiltration to vessel, nerve or local surrounding tissue are characteristic features of unequivocal carcinomas, tumors frequently associated with mortal outcome.

Mutations in the hyperparathyroidism 2 gene (HRPT2, $C D C 73$ ) have been established as one underlying genetic mechanism in the tumorigenesis of parathyroid carcinoma (1-4). Inactivating HRPT2 mutations are frequently revealed in somatic cells and/or in germ-line cells of these patients, the latter often in connection to a syndromic form of the disease known as the hyperparathyroidism-jaw tumor syndrome (HPT-JT, OMIM \#145001). By contrast HRPT2 mutations are uncommon in benign forms of PHPT $(5,6)$. Parafibromin, the protein product of HRPT2, has recently been linked to the Wingless type (Wnt) pathway through its nuclear association with B-catenin (7). In absence of Wnt signaling, $\beta$-catenin is phosphorylated and subsequently degraded by a protein complex consisting of Axin, adenomatous polyposis coli (APC) and glycogen synthase kinase 3- $\beta$ (GSK3- $\beta$ ) (8-10). Upon Wnt signaling, the inhibitory complex is dissociated and unphosphorylated (active) $B$ catenin accumulates in the cytoplasm and the nucleus. The association of B-catenin with parafibromin and members of the human PAF complex regulates transcription of target genes encoding e.g. the c-myc oncoprotein and the cell cycle protein cyclin D1.

Parafibromin has been evaluated as a putative diagnostic marker of malignant parathyroid disease, for which early diagnosis and extensive surgical treatment are essential to achieve long-term survival $(11,12)$. However, the lack of 
diagnostic tools has remained a dilemma in clinical practice, and therefore parathyroid carcinoma patients are often unrecognized until metastasis or recurrent disease is diagnosed. Most studies have shown strong parafibromin expression in parathyroid adenomas, together with frequent reduction or loss of immunoreactivity in carcinomas (13-16). Parafibromin immunostaining in parathyroid carcinomas often display a reduction in the amount of parafibrominpositive cells rather than a complete loss of immunoreactivity. Furthermore, cases with HRPT2 mutations recurrently display reduced immunoreactivity. These findings demonstrate the value but also the present difficulties to apply parafibromin immunostaining in clinical settings (16-18).

With the aim of further characterizing the molecular genetic background of parathyroid carcinoma, we have evaluated members of the Wnt pathway in malignant and benign PHPT. For this purpose we determined the immunohistochemical protein expression of APC, GSK3- $\beta, \beta$-catenin and cyclin D1 in a series of parathyroid carcinomas and adenomas, and compared the findings with expression of parafibromin and proliferation index. The findings support the involvement of Wnt pathway members in parathyroid carcinoma development and identify APC as a possible marker for identification of malignant PHPT.

\section{Materials and methods}

Patients and tissue samples. The study includes 13 unequivocal parathyroid carcinoma samples from 12 patients (Ca 1-12, Table I) that are part of a previously published historical material $(16,19,20)$. Histopathological classifications were according to the guidelines of the World Health Organization (WHO) (21). Thus, the diagnosis of unequivocal carcinoma was defined by distant metastasis, and/or local invasion of surrounding organs, and/or vascular/ neural invasion, and/or evidence of recurrence after parathyroidectomy. Parathyroid tumors with histological features indicating malignancy ('equivoval' cancer) but lacking the above criteria, was not used in this study because no extensive follow-up data concerning these tumors exists. Since an assembly of equivocal carcinomas represents a heterogeneous group of tumors, including benign as well as potentially malignant cases, long-term follow-up data are crucial in determining the true identity of these lesions and the interpretation of a negative or positive staining in such a case (21).

Among the 12 carcinoma patients investigated in this study, 5 had been diagnosed with local recurrence, 1 with distant metastasis, 7 with a primary carcinoma demonstrating vascular or neural infiltration and 3 patients died of the disease. These data are detailed for each case in reference 16 (Table I).

Furthermore, the study comprises parathyroid adenomas and non-tumorous control tissues collected with informed consent and ethical approval at Karolinska University Hospital in Stockholm. Eighteen samples of sporadic parathyroid adenomas (Ad 1-18) were from 18 patients undergoing surgery for PHPT, who all displayed either elevated serum calcium levels and/or elevated PTH levels preoperatively (Table I). Paraffin sections and frozen tissue samples from
4 sporadic cystic parathyroid adenomas (denoted $\mathrm{Ctrl}_{\mathrm{Ad}} 1-4$ ) were used as controls to optimize the antibody dilutions. $\mathrm{Ctrl}_{\mathrm{ad}}$ 1-4 have previously been shown to exhibit wild-type HRPT2 gene sequence and express parafibromin at the $\sim 60 \mathrm{kDa}$ level (6). Hence we could correlate protein expression to immunohistochemical staining results in these four cases lacking alterations in the HRPT2/parafibromin axis, thereby optimizing the methodology for the subsequent Wnt protein members staining of $\mathrm{Ca}$ 1-12 and Ad 1-18. Furthermore, for the N-terminal APC antibody, a case of normal colon and two regular parathyroid adenomas on the same slide was used as controls to optimize the antigen retrieval protocol as well as in the subsequent immunostainings of Ca 1-12 and Ad 1-18. Furthermore, paraffinembedded samples of normal colon and colon cancer was mounted on the same slide and used as positive control for active $\beta$-catenin.

Expression patterns in non-tumorous parathyroid tissue were studied in adjacent normal parathyroid rims from 12 of the 18 adenoma cases (Ad 1-18 $8_{\text {NRim }}$ ). Non-tumorous parathyroid tissue pooled from three individual surgical biopsies $\left(\right.$ Norm $\left._{\text {pool }}\right)$ was investigated together with reference parathyroid adenomas (22) for active and C-terminal B-catenin expression using Western blot analysis.

Antibodies. The following primary antibodies were used: a rabbit monoclonal antibody directed against an N-terminal polypeptide derived from exon 3 of human APC (EP701Y, Abcam, Cambridge, UK); a mouse monoclonal antibody targeting the C-terminal part of human APC (EMM43, Abcam); a rabbit monoclonal antibody directed towards the N-terminal part of human GSK3-ß (Y174, Abcam); a mouse monoclonal antibody raised against amino acids (aa) 680-781 at the C-terminus of human B-catenin (E-5, \#sc-7963, Santa Cruz Biotechnology, CA, USA); a mouse monoclonal antibody against active (unphosphorylated) $B$-catenin targeting aa 36-44 (8E7, \#05-665, Upstate/Millipore, MA, USA); a rabbit monoclonal antibody against human cyclin D1 (SP4, \#RM-9104-F, Neomarkers, CA, USA); a monoclonal mouse antibody targeting the human proliferation marker Ki-67 (MIB-1, Dako, Glostrup, Denmark); a mouse monoclonal anti-ß-actin antibody (AC-15, \#A1978, Sigma-Aldrich, MO, USA); and a mouse monoclonal $\alpha$-actinin antibody (MAB 1682, Chemicon, CA, USA).

The N-terminal APC antibody EP701Y detects full length APC of $\sim 311 \mathrm{kDa}$, the short isoform 2 of $\sim 304 \mathrm{kDa}$ which lacks 101 aa encoded by part of exon 9 , as well as an $\sim 160 \mathrm{kDa}$ product lacking epitopes encoded by the first and last exons (23). EMM43 targets a sequence within a 251 aa region of the C-terminus of the human APC protein. Hence, the C-terminal EMM43 antibody is predicted to detect full length APC in addition to the short isoform 2, but not the alternative $\sim 160 \mathrm{kDa}$ product. The E-5 antibody for C-terminal $\beta$-catenin shows a single $\sim 92 \mathrm{kDa}$ product, while anti-active $B$-catenin $8 \mathrm{E} 7$ detects a $\sim 92 \mathrm{kDa}$ product and in addition a larger product (10).

The dilution factor applied for immunohistochemistry with the antibodies for N-terminal APC, GSK3- 3 , C-terminal $\beta$-catenin and cyclin D1 was determined from parallel Western blot and immunohistochemical analyses of $\mathrm{Ctrl}_{\mathrm{Ad}} 1-4$. 
Table I. Clinical information for the parathyroid tumor cases studied.

\begin{tabular}{|c|c|c|c|c|c|c|}
\hline $\begin{array}{l}\text { Case } \\
\text { no. }\end{array}$ & $\begin{array}{c}\text { Tissue } \\
\text { analyzed }\end{array}$ & Sex & $\begin{array}{l}\text { Age } \\
\text { at op. }\end{array}$ & $\begin{array}{c}\mathrm{S}-\mathrm{Ca}^{\mathrm{a}} \\
(\mathrm{mmol} / \mathrm{l})\end{array}$ & $\begin{array}{l}\text { Weight/ } \\
\text { size }\end{array}$ & $\begin{array}{c}\text { Previously } \\
\text { published in ref }\end{array}$ \\
\hline \multicolumn{7}{|c|}{$\begin{array}{l}\text { Parathyroid } \\
\text { carcinomas }\end{array}$} \\
\hline $\mathrm{Ca} 1$ & Primary tumor & M & 59 & 4.0 & $5 \mathrm{~cm}$ & (16) - No T22 \\
\hline $\mathrm{Ca} 2$ & Primary tumor & M & 57 & 3.3 & $2.7 \mathrm{~cm}$ & (16) - No T13 \\
\hline $\mathrm{Ca} 3$ & Primary tumor & $\mathrm{F}$ & 63 & 3.2 & $1.3 \mathrm{~cm}$ & (16) - No T15 \\
\hline $\mathrm{Ca} 4$ & Primary tumor & $\mathrm{F}$ & 85 & Elevated & $3 \mathrm{~cm}$ & (16) - No T18 \\
\hline Ca 5 & Local recurrence & F & 78 & 5.0 & $6,600 \mathrm{mg}$ & (16) - No T9 \\
\hline $\mathrm{Ca} 6 \mathrm{a}$ & Local recurrence & F & 60 & - & - & (16) - No T7 \\
\hline $\mathrm{Ca} 6 \mathrm{~b}$ & Neck metastasis & F & 61 & - & - & (16) - No T4 \\
\hline $\mathrm{Ca} 7$ & Primary tumor & M & 74 & 3.2 & $3 \mathrm{~cm}$ & (16) - No T16 \\
\hline $\mathrm{Ca} 8$ & Primary tumor & $\mathrm{F}$ & 58 & 3.3 & $2 \mathrm{~cm}$ & (16) - No T12 \\
\hline $\mathrm{Ca} 9$ & Primary tumor & $\mathrm{F}$ & 64 & 3.0 & $25,000 \mathrm{mg}$ & (16) - No T11 \\
\hline Ca 10 & Primary tumor & M & 78 & 3.1 & $5 \mathrm{~cm}$ & (16) - No T17 \\
\hline Ca 11 & Primary tumor & M & 78 & 4.5 & $3.1 \mathrm{~cm}$ & (16) - No T19 \\
\hline $\mathrm{Ca} 12$ & Primary tumor & $\mathrm{F}$ & 32 & 3.9 & $3,100 \mathrm{mg}$ & (16) - No T14 \\
\hline
\end{tabular}

Parathyroid

adenomas

\begin{tabular}{|c|c|c|c|c|c|c|}
\hline Ad 1 & Primary tumor & $\mathrm{F}$ & 67 & $2.60^{c}$ & $1,523 \mathrm{mg}$ & (16) \\
\hline $\operatorname{Ad} 2$ & Primary tumor & $\mathrm{F}$ & 46 & 2.45 & $1,700 \mathrm{mg}$ & (16) \\
\hline Ad 3 & Primary tumor & M & 63 & $1.49^{\mathrm{b}}$ & $414 \mathrm{mg}$ & (16) \\
\hline $\operatorname{Ad} 4$ & Primary tumor & $\mathrm{F}$ & 45 & 2.81 & $418 \mathrm{mg}$ & (16) \\
\hline Ad 5 & Primary tumor & M & 54 & $2.56^{\mathrm{c}}$ & $597 \mathrm{mg}$ & (16) \\
\hline Ad 6 & Primary tumor & $\mathrm{F}$ & 71 & $2.50^{\mathrm{c}}$ & $900 \mathrm{mg}$ & (16) \\
\hline Ad 7 & Primary tumor & $\mathrm{F}$ & 66 & $2.54^{\mathrm{c}}$ & $858 \mathrm{mg}$ & (16) \\
\hline Ad 8 & Primary tumor & M & 48 & 2.83 & $750 \mathrm{mg}$ & (16) \\
\hline Ad 9 & Primary tumor & $\mathrm{F}$ & 67 & $1.25^{\mathrm{b}}$ & $347 \mathrm{mg}$ & (16) \\
\hline Ad 10 & Primary tumor & $\mathrm{F}$ & 51 & 2.71 & $600 \mathrm{mg}$ & (16) \\
\hline Ad 11 & Primary tumor & $\mathrm{F}$ & 37 & 2.61 & $465 \mathrm{mg}$ & (16) \\
\hline Ad 12 & Primary tumor & $\mathrm{F}$ & 61 & $2.40^{c}$ & $777 \mathrm{mg}$ & (16) \\
\hline Ad 13 & Primary tumor & M & 36 & 2.69 & $388 \mathrm{mg}$ & (16) \\
\hline Ad 14 & Primary tumor & $\mathrm{F}$ & 52 & $2.51^{\mathrm{c}}$ & $1,470 \mathrm{mg}$ & (16) \\
\hline Ad 15 & Primary tumor & $\mathrm{F}$ & 63 & $2.57^{\mathrm{c}}$ & $720 \mathrm{mg}$ & (16) \\
\hline Ad 16 & Primary tumor & $\mathrm{F}$ & 64 & 2.63 & $1,130 \mathrm{mg}$ & (16) \\
\hline Ad 17 & Primary tumor & $\mathrm{F}$ & 57 & 2.74 & $196 \mathrm{mg}$ & (16) \\
\hline Ad 18 & Primary tumor & $\mathrm{F}$ & 45 & 2.79 & $290 \mathrm{mg}$ & (16) \\
\hline
\end{tabular}

${ }^{\mathrm{a}}$ Reference range (total S-Ca 2.20-2.60); ${ }^{\mathrm{b}}$ Free fraction reference range (1.17-1.29); ${ }^{\mathrm{c}} \mathrm{S}-\mathrm{Ca}$ values where within reference range but exhibited elevated PTH levels $(>55 \mathrm{ng} / \mathrm{l})$. - , not determined.

Western blot analyses. Western blot analyses of total protein extracts from parathyroid control adenomas and non-tumorous tissues were done essentially as previously described (6). In brief, samples were electrophoresed in $10 \%$ Tricine gels (Invitrogen, CA, USA), blotted onto nitrocellulose membranes and stained with ATX Ponceau S Red solution (SigmaAldrich). Membranes were then incubated overnight at $4^{\circ} \mathrm{C}$ with the primary antibodies for N-terminal APC (EP701Y, 1:300), GSK3-ß (Y174, 1:500), C-terminal ß-catenin (E-5,
$1: 100)$, active $\beta$-catenin $(8 \mathrm{E} 7,1: 2,000), \beta$-actin $(1: 50,000)$ or $\alpha$-actinin (1:500) and subsequently incubated for $1.5 \mathrm{~h}$ with the respective secondary HRP-conjugated antibody (goat anti-rabbit IgG 1:12,500, goat anti-mouse IgG 1:10,000, BioRad Laboratories, CA, USA). Ponceau staining and incubation of membranes with the $\alpha$-actinin or $\beta$-actin antibody served as controls of equal loading and protein presence. Kaleidoscope Prestained Standard (161-0324, Bio-Rad) was used as a molecular size marker. Images were contrast enhanced and 
Table II. Immunohistochemical expression patterns in normal parathyroid rims.

\begin{tabular}{|c|c|c|c|c|c|c|c|c|c|c|c|}
\hline \multirow{2}{*}{$\begin{array}{l}\text { Normal } \\
\text { parathyroid } \\
\text { no. }\end{array}$} & \multirow{2}{*}{$\begin{array}{c}\text { From } \\
\text { adenoma } \\
\text { no. }\end{array}$} & \multirow{2}{*}{$\begin{array}{c}\text { N-term APC } \\
\text { (EP701Y) } \\
\text { Cytoplasm }\end{array}$} & \multirow{2}{*}{$\begin{array}{c}\text { C-term APC } \\
\text { (EMM43) } \\
\text { Cytoplasm }\end{array}$} & \multirow{2}{*}{$\begin{array}{c}\text { GSK3-B } \\
\text { (Y174) } \\
\text { Cytoplasm }\end{array}$} & \multicolumn{3}{|c|}{ C-terminal B-catenin (E-5) } & \multicolumn{3}{|c|}{ Active 3 -catenin (8E7) } & \multirow{2}{*}{$\begin{array}{c}\text { Cyclin D1 } \\
\text { (SP4) } \\
\text { Nucleus }\end{array}$} \\
\hline & & & & & Cytoplasm & Membrane & Nucleus & Cytoplasm & Membrane & Nucleus & \\
\hline Ad $2_{\text {NRim }}$ & Ad 2 & Pos. & Pos. & Pos. & Pos. & Pos. & Neg. & Pos. & Neg. & Pos./Neg. & $5 \%$ \\
\hline Ad $3_{\text {NRim }}$ & Ad 3 & Pos. & Pos. & Pos. & Pos. & Pos. & Neg. & Pos. & Neg. & Pos./Neg. & $9 \%$ \\
\hline Ad $4_{\text {NRim }}$ & $\operatorname{Ad} 4$ & Pos. & Pos. & Pos. & Pos. & Pos. & Neg. & Pos. & Neg. & Pos./Neg. & $14 \%$ \\
\hline Ad $5_{\text {NRim }}$ & Ad 5 & Pos. & Pos. & Pos. & Pos. & Pos. & Neg. & Pos. & Neg. & Pos./Neg. & $9 \%$ \\
\hline Ad $6_{\text {NRim }}$ & Ad 6 & Pos. & Pos. & Pos. & Pos. & Pos. & Neg. & Pos. & Neg. & Pos./Neg. & $19 \%$ \\
\hline Ad $8_{\text {NRim }}$ & Ad 8 & Pos. & Pos. & Pos. & Pos. & Pos. & Neg. & Pos. & Neg. & Pos./Neg. & $10 \%$ \\
\hline Ad $9_{\text {NRim }}$ & Ad 9 & Pos. & Pos. & Pos. & Pos. & Pos. & Neg. & Pos. & Neg. & Pos./Neg. & $13 \%$ \\
\hline Ad $12_{\text {NRim }}$ & Ad 12 & Pos. & Pos. & Pos. & Pos. & Pos. & Neg. & Pos. & Neg. & Pos./Neg. & $10 \%$ \\
\hline Ad $15_{\text {NRim }}$ & Ad 15 & Pos. & Pos. & Pos. & Pos. & Pos. & Neg. & Pos. & Neg. & Pos./Neg. & $17 \%$ \\
\hline Ad $16_{\text {NRim }}$ & Ad 16 & Pos. & Pos. & Pos. & Pos. & Pos. & Neg. & Pos. & Neg. & Pos./Neg. & $9 \%$ \\
\hline Ad $17_{\text {NRim }}$ & Ad 17 & Pos. & Pos. & Pos. & Pos. & Pos. & Neg. & Pos. & Neg. & Pos./Neg. & $14 \%$ \\
\hline Ad $18_{\text {NRim }}$ & Ad 18 & Pos. & Pos. & Pos. & Pos. & Neg. & Neg. & Pos. & Neg. & Pos./Neg. & $9 \%$ \\
\hline
\end{tabular}

subsequently cropped using the Adode Photoshop 7.0 software (Adobe Systems Incorporated, CA, USA). Results from Western blot analysis of cyclin D1 expression in $\mathrm{Ctrl}_{\mathrm{Ad}} 1-4$ have been previously published (6).

Immunohistochemistry. Paraffin sections $(4 \mu \mathrm{m})$ were deparaffinized, rehydrated and treated in preheated citrate buffer pH 6.0 (Dako) at $95^{\circ} \mathrm{C}$ for $20 \mathrm{~min}$ in a microwave oven. To optimize the antigen retrieval protocol for the APC immunostainings, control experiments with normal colon and two parathyroid adenomas on the same slide were assessed using the N-terminal APC antibody EP701Y and the following three parameters: no antigen retrieval, $10 \mathrm{~min}$ and $20 \mathrm{~min}$ in citrate buffer respectively. In our laboratory settings, we acquired the expected immunoreactivity using 10 and $20 \mathrm{~min}$ of citrate treatment, whereas the signals were very low or absent using no antigen retrieval. There were no differences between 10 and 20 min treatment regarding APC staining intensity (data not shown).

The slides were incubated for $30 \mathrm{~min}$ in $0.3 \%$ hydrogen peroxide and blocked in $1 \%$ BSA with $0.01 \%$ Na-azide for 1 h. Endogenous biotin was neutralized using the Avidin/ Biotin Blocking Kit (SP-2001, Vector Laboratories, Burlingame, CA, USA). Slides were then incubated overnight at $4^{\circ} \mathrm{C}$ with the respective primary antibodies for $\mathrm{N}$-terminal APC (EP701Y, 1:100), C-terminal APC (EMM43, 1:40), GSK3-ß (Y174, 1:200), C-terminal ß-catenin (E-5, 1:100), active $\beta$-catenin $(8 \mathrm{E} 7,1: 200)$, cyclin D1 (SP4, 1:100) and Ki-67 (MIB-1, 1:100) diluted in 1\% BSA, followed by the biotinylated secondary antibody goat anti rabbit IgG or horse anti-mouse $\operatorname{IgG}$ at 1:200 and 1:700 respectively (BA1000/BA-2000, Vector Laboratories) for $45 \mathrm{~min}$. After incubation with the avidin-biotin-peroxidase complex (ABC) (Vectastain Elite Kit, Vector Laboratories) for $45 \mathrm{~min}$ and diaminobenzidine tetrahydrochloride for $6 \mathrm{~min}$, slides were counterstained with haematoxylin for $3 \mathrm{~min}$. Omission of the primary antibody served as negative control. Sections were analyzed using a Zeiss Axioskop microscope (Carl Zeiss,
Jena, Germany) equipped with Zeiss Plan-Neofluar objective lenses. The images were obtained using a ProgRes C12 Plus camera and the ProgRes Capture Pro 2.5 software program (Jenoptik, Jena, Germany).

Scoring of the immunoreactivity was performed for the entire section field independently by two of the authors (C.J. and A.H.), one of which was without knowledge of the sample classification (A.H.). For APC, GSK3- $\beta$ and $\beta$-catenin, samples scored as negative had no immunoreactivity in tumor cells, while in positive cases all or the vast majority of tumor cells exhibited strong immunoreactivity. Weak cases showed low level of immunoreactivity in a minority of tumor cells. To further validate our findings for APC, a subset of the negatively stained carcinomas and the positively stained adenomas were restained using the N-terminal APC antibody with identical results (data not shown). For cyclin D1, samples were scored by counting at least 1,000 cells from a total of 3 randomly selected grid areas of the sections in high power magnification (using x40 as objective). The cells were classified as having either positive or negative nuclear cyclin D1 expression. Furthermore, all parathyroid carcinomas enlisted in this study except $\mathrm{Ca} 5,6 \mathrm{a}$ and $6 \mathrm{~b}$ have previously been published with regards to Ki-67 immunoreactivity (20). Thus samples $\mathrm{Ca} 5,6 \mathrm{a}$ and $6 \mathrm{~b}$ were stained with the MIB-1 antibody and scored for this study by counting 1,000 cells in high power magnification (x40). Results from parafibromin immunohistochemistry in $\mathrm{Ca}$ 1-12 and Ad 1-18 have been previously published (16).

Statistical analysis of APC immunoreactivity. Statistical calculations were performed using the Statistica data analysis software system version 6 (Statsoft Inc, Tulsa, OK, USA) and a cut-off at $\mathrm{p}<0.05$ was applied for statistical significance. Fisher's exact test was applied to compare immunoreactivity for N-terminal anti-APC and C-terminal anti-APC between carcinomas and adenomas. Tumors were grouped as having either positive/weak or negative APC expression. For comparison between the $\mathrm{N}$-terminal 
Table III. Immunohistochemical expression patterns in parathyroid tumors.

\begin{tabular}{|c|c|c|c|c|c|c|c|c|c|}
\hline \multirow{2}{*}{$\begin{array}{l}\text { Case } \\
\text { no. }\end{array}$} & \multirow{2}{*}{$\begin{array}{l}\text { Parafibromin } \\
\text { from } \\
\text { ref. (16) }\end{array}$} & \multirow{2}{*}{$\begin{array}{l}\text { Ki-67 } \\
\text { from } \\
\text { ref. }(20)\end{array}$} & \multirow{2}{*}{$\begin{array}{l}\text { N-term APC } \\
(\text { EP701Y) } \\
\text { Cytoplasm }\end{array}$} & \multirow{2}{*}{$\begin{array}{l}\text { C-term APC } \\
\text { (EMM43) } \\
\text { Cytoplasm }\end{array}$} & \multirow{2}{*}{$\begin{array}{l}\text { GSK3-B } \\
\text { (Y174) } \\
\text { Cytoplasm }\end{array}$} & \multirow{2}{*}{$\frac{\text { C-terminal B-catenin (E-5) }}{\text { Cytoplasm Membrane Nucleus }}$} & \multicolumn{2}{|c|}{ Active $\beta$-catenin (8E7) } & \multirow{2}{*}{$\begin{array}{l}\text { Cyclin D1 } \\
\text { (SP4) } \\
\text { Nucleus }\end{array}$} \\
\hline & & & & & & & Cytoplasm Membrane & Nucleus & \\
\hline
\end{tabular}

Parathyroid

carcinomas

\begin{tabular}{|c|c|c|c|c|c|c|c|c|c|c|c|c|}
\hline $\mathrm{Ca} 1$ & Partial loss & $3.3 \%$ & Neg. & Pos. & Pos. & Pos. & Pos. & Pos./Neg. & Pos. & Neg. & Pos./Neg. & $35 \%$ \\
\hline $\mathrm{Ca} 2$ & Partial loss & $0.9 \%$ & Neg. & Pos. & Neg. & Pos. & Pos. & Neg. & Pos. & Neg. & Pos./Neg. & $7 \%$ \\
\hline Ca 3 & Partial loss & $1.0 \%$ & Neg. & Pos. & Pos. & Pos. & Pos. & Pos./Neg. & Pos. & Neg. & Pos./Neg. & $2 \%$ \\
\hline $\mathrm{Ca} 4$ & Partial loss & $0.3 \%$ & Neg. & Neg. & Neg. & Pos. & Pos. & Neg. & Pos. & Neg. & Pos./Neg. & $75 \%$ \\
\hline Ca 5 & Partial loss & $0.5 \%$ & Neg. & Pos. & Neg. & Pos. & Pos. & Neg. & Pos. & Neg. & Pos./Neg. & $21 \%$ \\
\hline $\mathrm{Ca} 6 \mathrm{a}$ & Pos. & $5.4 \%$ & Pos. & Pos. & Pos. & Pos. & Pos. & Neg. & Pos. & Neg. & Pos./Neg. & $7 \%$ \\
\hline $\mathrm{Ca} 6 \mathrm{~b}$ & Pos. & $12.0 \%$ & Weak & Pos. & Pos. & Pos. & Pos. & Neg. & Pos. & Neg. & Pos./Neg. & $45 \%$ \\
\hline $\mathrm{Ca} 7$ & Partial loss & $5.9 \%$ & Neg. & Neg. & Neg. & Pos. & Pos. & Neg. & Pos. & Neg. & Pos./Neg. & $25 \%$ \\
\hline Ca 8 & Partial loss & $3.7 \%$ & Neg. & Pos. & Pos. & Pos. & Pos. & Neg. & Pos. & Neg. & Pos./Neg. & $3 \%$ \\
\hline $\mathrm{Ca} 9$ & Partial loss & $1.0 \%$ & Neg. & Neg. & Pos. & Pos. & Pos. & Neg. & Pos. & Neg. & Pos./Neg. & $78 \%$ \\
\hline Ca 10 & Pos. & $1.5 \%$ & Neg. & Neg. & Pos. & Pos. & Pos. & Neg. & Pos. & Neg. & Pos./Neg. & $13 \%$ \\
\hline Ca 11 & Pos. & $6.0 \%$ & Pos. & Neg. & Pos. & Pos. & Pos. & Neg. & Pos. & Neg. & Pos./Neg. & $45 \%$ \\
\hline Ca 12 & Partial loss & $7.8 \%$ & Pos. & Neg. & Pos. & Pos. & Pos. & Neg. & Pos. & Neg. & Pos./Neg. & $21 \%$ \\
\hline \multirow{2}{*}{\multicolumn{13}{|c|}{$\begin{array}{l}\text { Parathyroid } \\
\text { adenomas }\end{array}$}} \\
\hline & & & & & & & & & & & & \\
\hline Ad 1 & Pos. & n.d. & Pos. & Pos. & Pos. & Pos. & Pos. & Neg. & Pos. & Neg. & Pos./Neg. & $64 \%$ \\
\hline Ad 2 & Pos. & n.d. & Pos. & Pos. & Pos. & Pos. & Pos. & Neg. & Pos. & Neg. & Pos./Neg. & $6 \%$ \\
\hline Ad 3 & Pos. & n.d. & Pos. & Pos. & Neg. & Pos. & Pos. & Neg. & Pos. & Neg. & Pos./Neg. & $46 \%$ \\
\hline Ad 4 & Pos. & n.d. & Pos. & Pos. & Pos. & Pos. & Pos. & Neg. & Pos. & Neg. & Pos./Neg. & $6 \%$ \\
\hline Ad 5 & Pos. & n.d. & Pos. & Pos. & Pos. & Pos. & Pos. & Neg. & Pos. & Neg. & Pos./Neg. & $44 \%$ \\
\hline Ad 6 & Pos. & n.d. & Pos. & Pos. & Pos. & Pos. & Pos. & Neg. & Pos. & Neg. & Pos./Neg. & $50 \%$ \\
\hline Ad 7 & Pos. & n.d. & Pos. & Pos. & Pos. & Pos. & Pos. & Neg. & Pos. & Neg. & Pos./Neg. & $100 \%$ \\
\hline Ad 8 & Pos. & n.d. & Pos. & Pos. & Pos. & Pos. & Pos. & Neg. & Pos. & Neg. & Pos./Neg. & $31 \%$ \\
\hline Ad 9 & Pos. & n.d. & Pos. & Pos. & Pos. & Pos. & Pos. & Neg. & Pos. & Neg. & Pos./Neg. & $18 \%$ \\
\hline Ad 10 & Pos. & n.d. & Pos. & Pos. & Pos. & Pos. & Pos. & Neg. & Pos. & Neg. & Pos./Neg. & $12 \%$ \\
\hline Ad 11 & Pos. & n.d. & Pos. & Pos. & Pos. & Pos. & Pos. & Neg. & Pos. & Neg. & Pos./Neg. & $16 \%$ \\
\hline Ad 12 & Pos. & n.d. & Pos. & Pos. & Pos. & Pos. & Pos. & Neg. & Pos. & Neg. & Pos./Neg. & $10 \%$ \\
\hline Ad 13 & Pos. & n.d. & Pos. & Pos. & Pos. & Pos. & Pos. & Neg. & Pos. & Neg. & Pos./Neg. & $39 \%$ \\
\hline Ad 14 & Pos. & n.d. & Pos. & Pos. & Pos. & Pos. & Pos. & Neg. & Pos. & Neg. & Pos./Neg. & $100 \%$ \\
\hline Ad 15 & Pos. & n.d. & Pos. & Pos. & Pos. & Pos. & Pos. & Neg. & Pos. & Neg. & Pos./Neg. & $13 \%$ \\
\hline Ad 16 & Pos. & n.d. & Pos. & Pos. & Pos. & Pos. & Pos. & Neg. & Pos. & Neg. & Pos./Neg. & $19 \%$ \\
\hline Ad 17 & Pos. & n.d. & Pos. & Pos. & Pos. & Pos. & Pos. & Neg. & Pos. & Neg. & Pos./Neg. & $8 \%$ \\
\hline Ad 18 & Pos. & n.d. & Pos. & Pos. & Pos. & Pos. & Pos. & Neg. & Pos. & Neg. & Pos./Neg. & $100 \%$ \\
\hline
\end{tabular}

n.d., not determined.

APC antibody in the current study and previously published parafibromin staining results in unequivocal carcinomas (16), McNemar's $\chi^{2}$ test and Cohen's Kappa test were applied. To allow comparison, cases with 'partial loss' of parafibromin staining were classed as 'negative'. Furthermore, the sensitivity and the specificity for loss of APC immunoreactivity were calculated, and the negative and positive predictive values (NPV and PPV) were determined assuming a prevalence of $1 \%$ for parathyroid carcinoma in PHPT (21) Finally, comparison of adenomas and carcinomas regarding cyclin D1 immunoreactivity was performed using the MannWhitney U test.

\section{Results}

In this study we determined the immunohistochemical expression of APC, GSK3- $\beta$, $\beta$-catenin as well as cyclin D1 in non-tumorous parathyroid tissue (Table II) and parathyroid carcinomas and adenomas (Table III) using monoclonal antibodies. The clinical characteristics are detailed for each 
$\mathbf{A}$

\section{Anti-APC (EP701Y)}
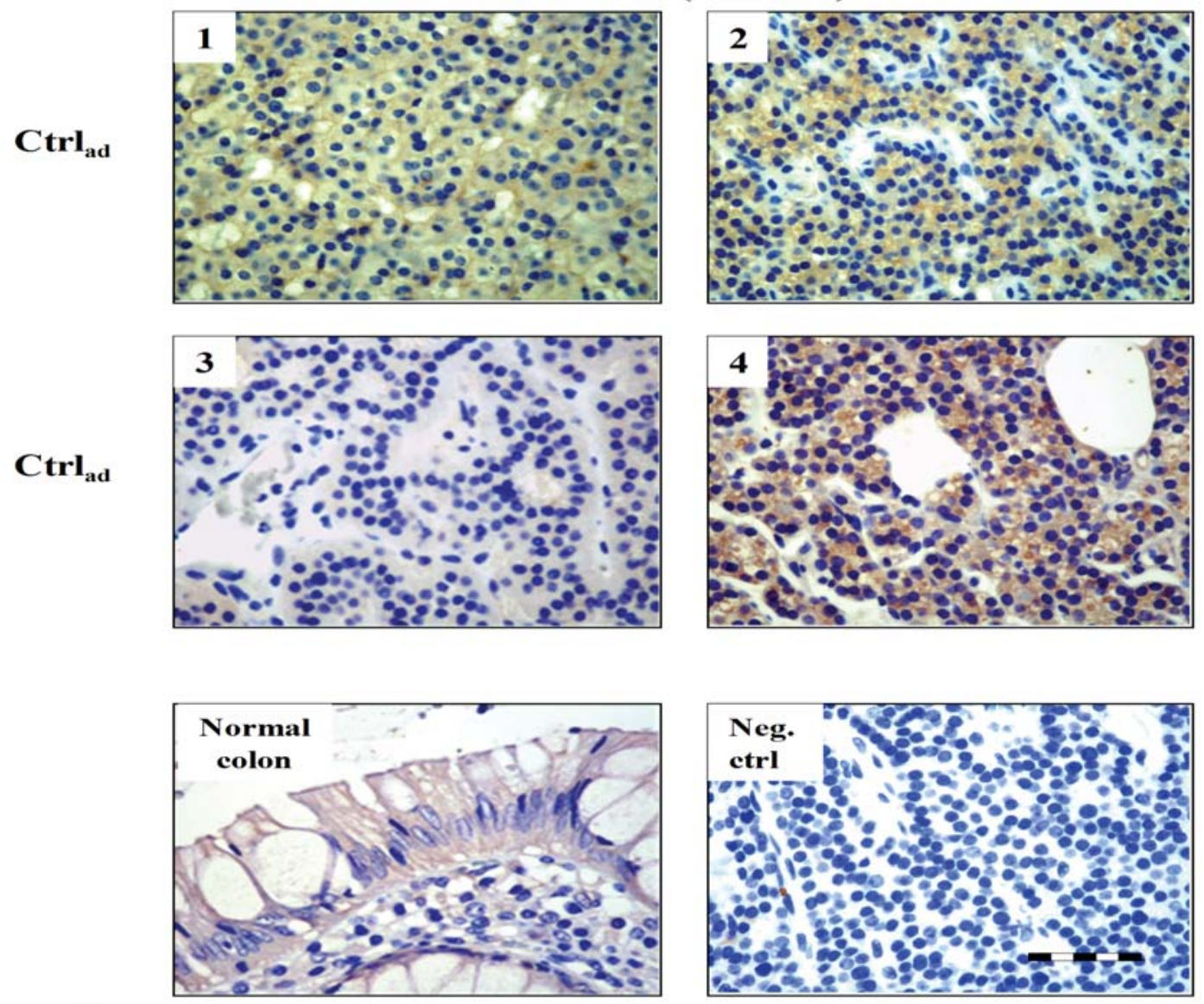

B

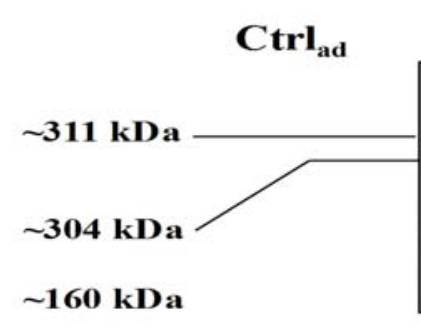

$\sim 100 \mathrm{kDa}$

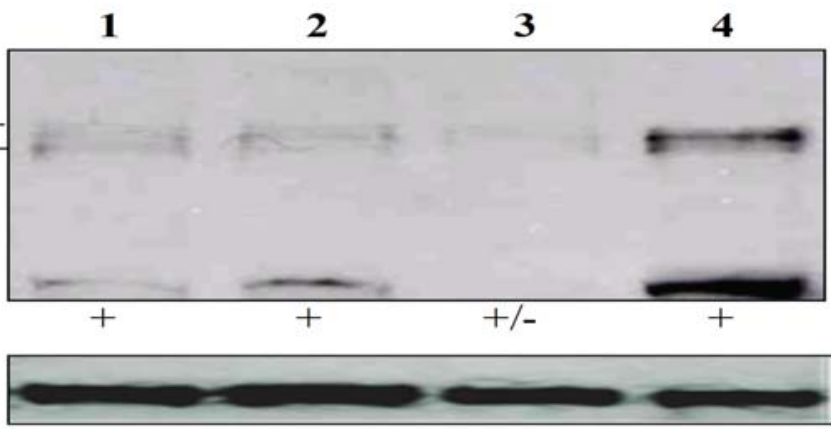

APC

APC

\section{a-actinin}

Figure 1. Control experiments of the N-terminal APC antibody dilutions using parallel (A) immunohistochemistry and (B) Western blot analysis of four control parathyroid adenomas $\left(\mathrm{Ctrl}_{\mathrm{Ad}} 1-4\right)$. (A) The staining was located to the cytoplasm while the nuclei and surrounding fibrous tissue was negative for APC immunoreactivity. A normal colon was included as a reference for APC immunoreactivity. Omission of the primary antibody served as negative control (neg. ctrl). The striped line represents $50 \mu \mathrm{m}$ and all images are magnified x300. (B) The $\sim 311 \mathrm{kDa}$ and $\sim 304 \mathrm{kDa}$ products represent the full length APC and short isoform 2 respectively. The $\sim 160 \mathrm{kDa}$ product corresponds to the alternative form lacking corresponding epitopes of the first and last exons of the APC gene (23). '+' indicates strong expression and ' $+/-$ ' denotes weak expression. $\alpha$-actinin is a cytoplasmatic protein of $\sim 100 \mathrm{kDa}$ used as a control of equal protein loading between lanes.

case in Table I and existing data for parafibromin expression (16) and Ki-67 index (20) are given in Table III.

Expression in non-tumorous parathyroid tissues and controls. In control experiments for the antibodies targeting $\mathrm{N}$-terminal APC, GSK3- $\beta$, active $B$-catenin, and C-terminal $\beta$-catenin, products of the expected molecular weights were detected (Figs. 1 and 3). In addition, the obtained immunohistochemical staining intensity for each $\mathrm{Ctrl}_{\mathrm{Ad}}$ 1-4 was in agreement with the respective Western band intensity (Figs. 1 and 3). Western blot application of the cyclin D1 antibody has been previously published (6). Cytoplasmic APC immunoreactivity was demonstrated in all cells of normal colon (Fig. 1) and reference parathyroid adenomas on the same slide used as a positive control. Similarly, active ß-catenin exhibited the expected staining patterns in positive controls from normal colon and colon cancer (Fig. 3A). However, no expression was observed after omission of the primary antibodies (Figs. 1 and 3).

The expression in non-tumorous parathyroid was determined on normal parathyroid rims present within the slides for 12 of the 18 adenoma cases studied (Table II). For N-terminal 


\section{EP701Y anti-APC}
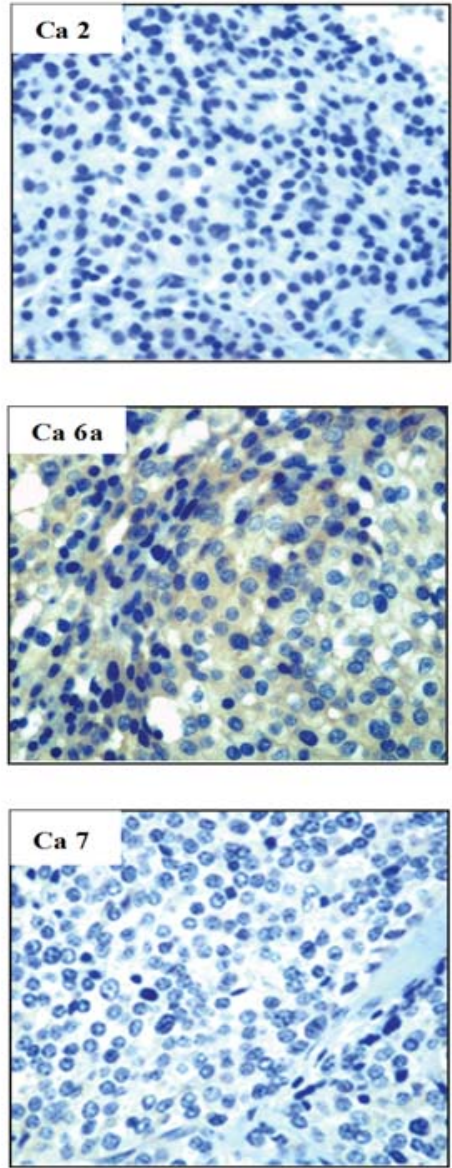

\section{EMM43 anti-APC}

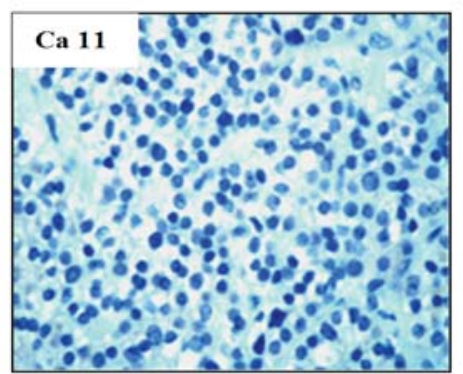

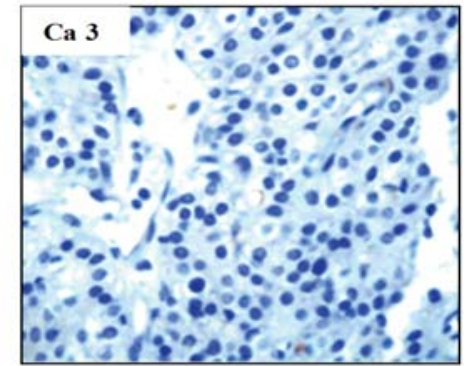
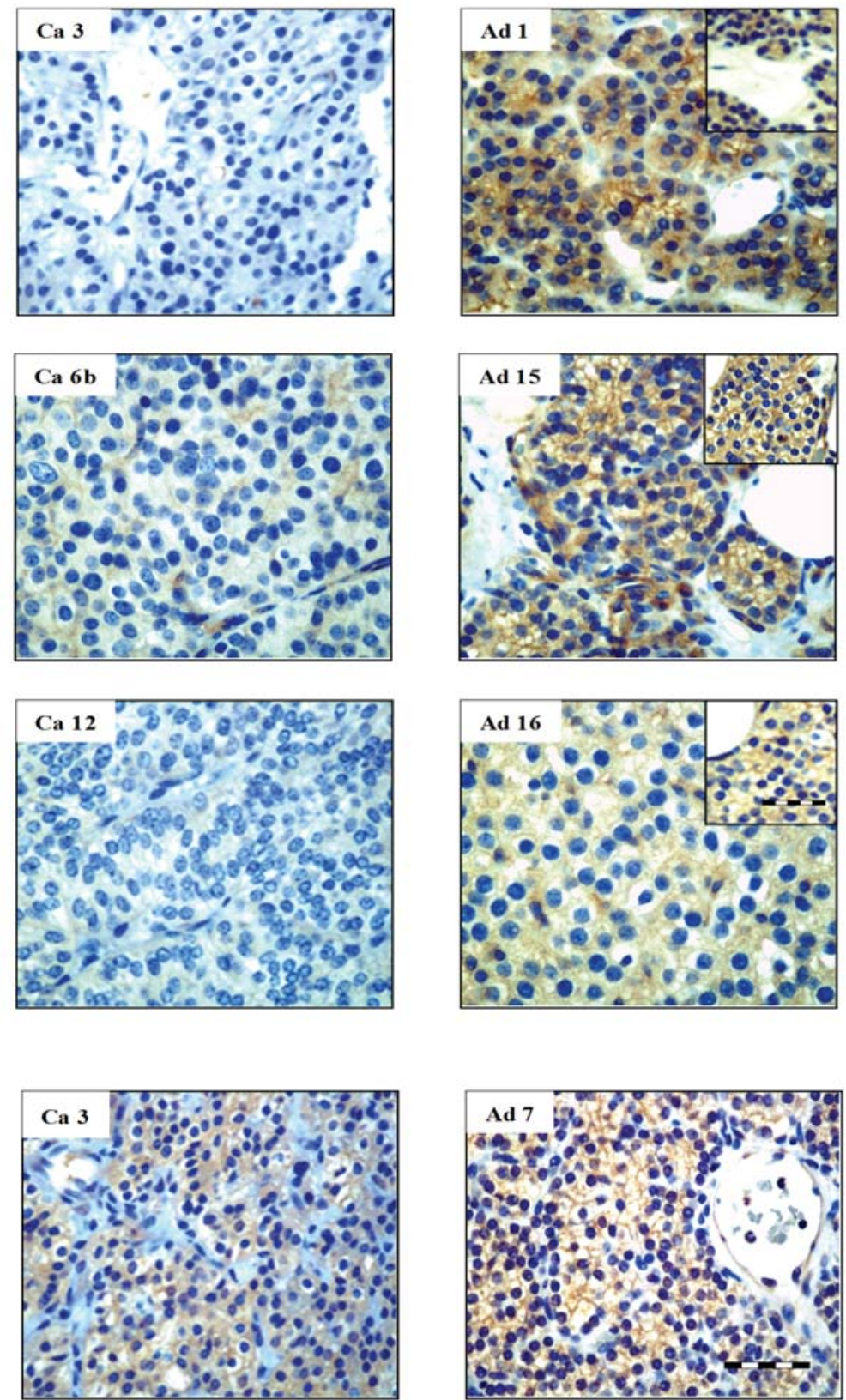

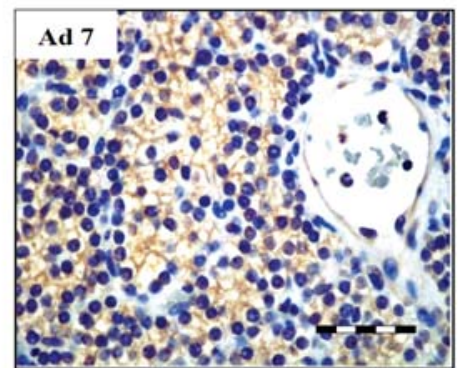

Figure 2. Photomicrographs showing results from APC immunohistochemistry in parathyroid adenomas (Ad) and carcinomas (Ca) using the N-terminal and C-terminal APC antibodies. Prominent staining was observed in the cytoplasm of all positive cases, while nuclei and fibrous tissue remained unstained. Using the N-terminal antibody, Ca 2, 3 and 7 demonstrate negative immunostaining, Ca 6 b exhibit weak staining, and Ca 6 a and 12 exemplify carcinomas with positive APC immunoreactivity. Ad 1, 15 and 16 show positive APC immunostaining of the tumor cells and normal glandular rims (inserts). For the the C-terminal antibody, Ca 11 is negative for APC immunoreactivity while Ca 3 and Ad 7 are two examples of positive APC staining. The striped line represents $50 \mu \mathrm{m}$ and all images are magnified $\mathrm{x} 240$, while the inserts are magnified $\mathrm{x} 180$.

and C-terminal APC as well as GSK3- $\beta$, all normal parathyroid rims showed cytoplasmic immunoreactivity in all cells (Table II, Fig. 2). Normal parathyroid rims were positive for cytosolic active $\beta$-catenin in all cells, while the nuclei showed a mixed pattern of positive and negative staining (Fig. 4). For C-terminal ß-catenin, all normal parathyroid rims displayed pronounced membranous as well as cytoplasmic staining in all cells, whereas the nuclei were negative. When evaluating the nuclear staining a high magnification (using a x40 objective) was applied to discriminate between stained and unstained nuclei.
Expression of active and C-terminal $\beta$-catenin in surgical biopsies of non-tumorous parathyroid was also demonstrated by Western blot analysis (Fig. 3D). Cyclin D1 showed nuclear staining in 5-19\% of normal parathyroid cells (Table II).

Loss of APC and GSK3- $\beta$ in parathyroid tumors. All 18 sporadic parathyroid adenomas showed uniform APC immunoreactivity in virtually all tumor cells (Ad 1-18, Table III). Similar results were obtained using both APC antibodies (Fig. 2). The staining was located in the cytoplasm, while 
$\mathbf{A}$

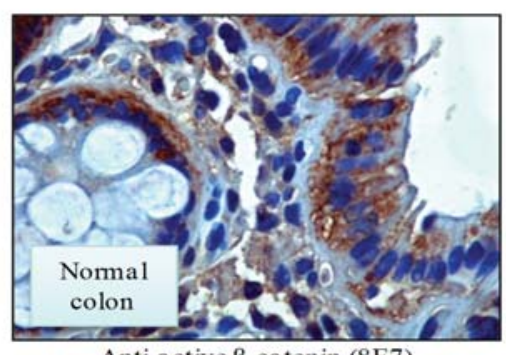

Anti-active $\beta$-catenin (8E7)

Controls for C-terminal $\beta$-catenin

B

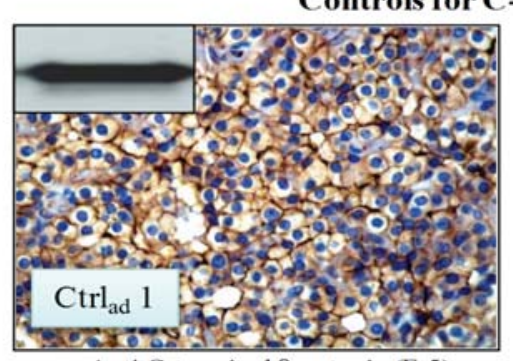

Anti-C-terminal $\beta$-catenin (E-5)

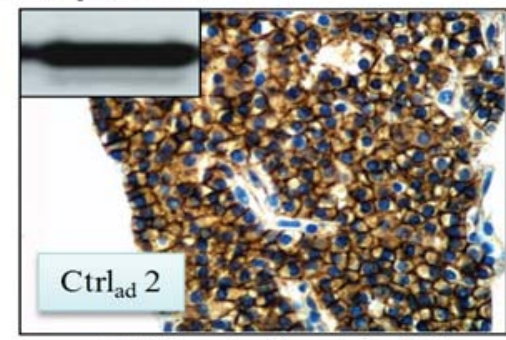

Anti-C-terminal $\beta$-catenin (E-5)

C

Negative control

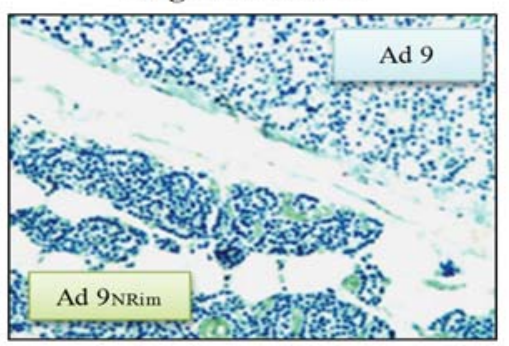

D

Western blot analysis of normal parathyroid and reference adenomas
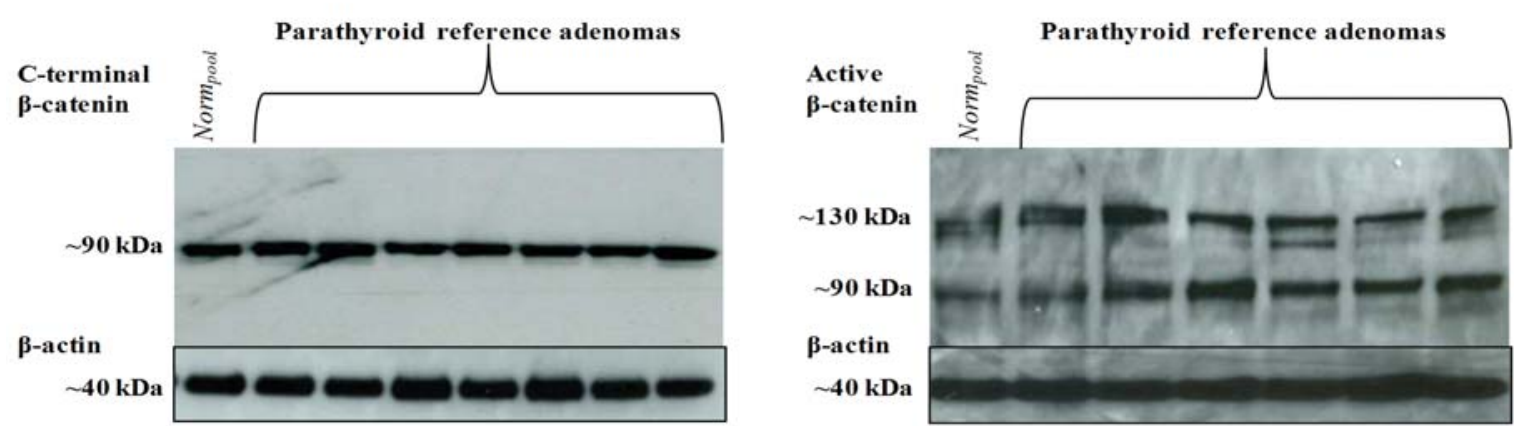

Figure 3. Control experiments for the antibodies detecting active B-catenin and C-terminal B-catenin. (A) Immunohistochemical detection of active (unphosphorylated) B-catenin in cytoplasm of normal colon and cytoplasm plus nuclei of colon cancer. (B) Expression of C-terminal B-catenin levels demonstrated by Western blot (inserts) and immunohistochemistry in control parathyroid adenomas $\mathrm{Ctrl}_{\mathrm{Ad}} 1$ and 2 . The protein localizes to the cellular membrane and cytoplasm. (C) Negative control by omission of primary antibody. (D) Western blot analyses of pooled non-tumorous parathyroid tissues and individual reference parathyroid adenomas on separate filters demonstrating product(s) corresponding to the expected size(s) for C-terminal and active $\beta$-catenin, respectively. Incubation with anti- $\beta$-actin was used as loading control.

nuclear expression was not detected. By contrast, 11 of the parathyroid carcinoma cases were completely negative for APC immunoreactivity, as revealed by either the Nterminal or C-terminal antibodies or both (Table III). With the N-terminal antibody, three carcinomas showed uniform cytoplasmic staining in all tumor cells $(\mathrm{Ca} 6 \mathrm{a}, 11,12)$, with similar range of intensity as seen in Ad 1-18. The metastasis $\mathrm{Ca} 6 \mathrm{~b}$ (derived from the same patient as the primary tumor $\mathrm{Ca}$ 6a) exhibited weak APC expression in a minority of cells.
Hence patient Ca 6 was classified as positive for APC expression, since both tumors ( $a$ and $b$ ) displayed APC immunoreactivity, albeit at different levels. For the Cterminal antibody, the remaining 6 cases were positive for APC immunoreactivity, exhibiting comparable intensity as Ad 1-18.

Cytoplasmic immunoreactivity of GSK3-ß was observed in all cells in $17 / 18$ adenomas and in carcinomas from $8 / 12$ patients (Table III). Loss of GSK3-ß was hence demonstrated 
Anti-activated $\beta$-catenin (8E7)
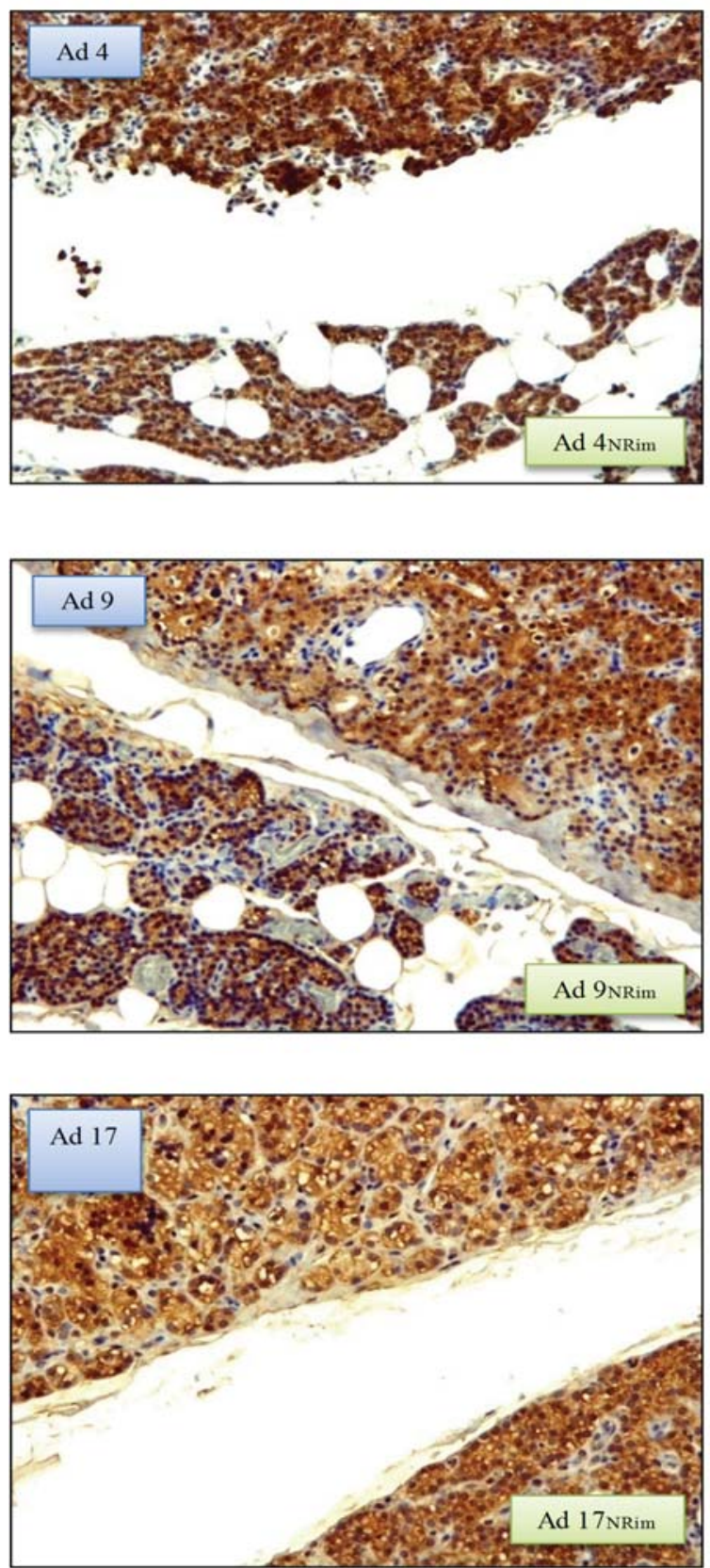

Anti-C-terminal $\beta$-catenin (E-5)
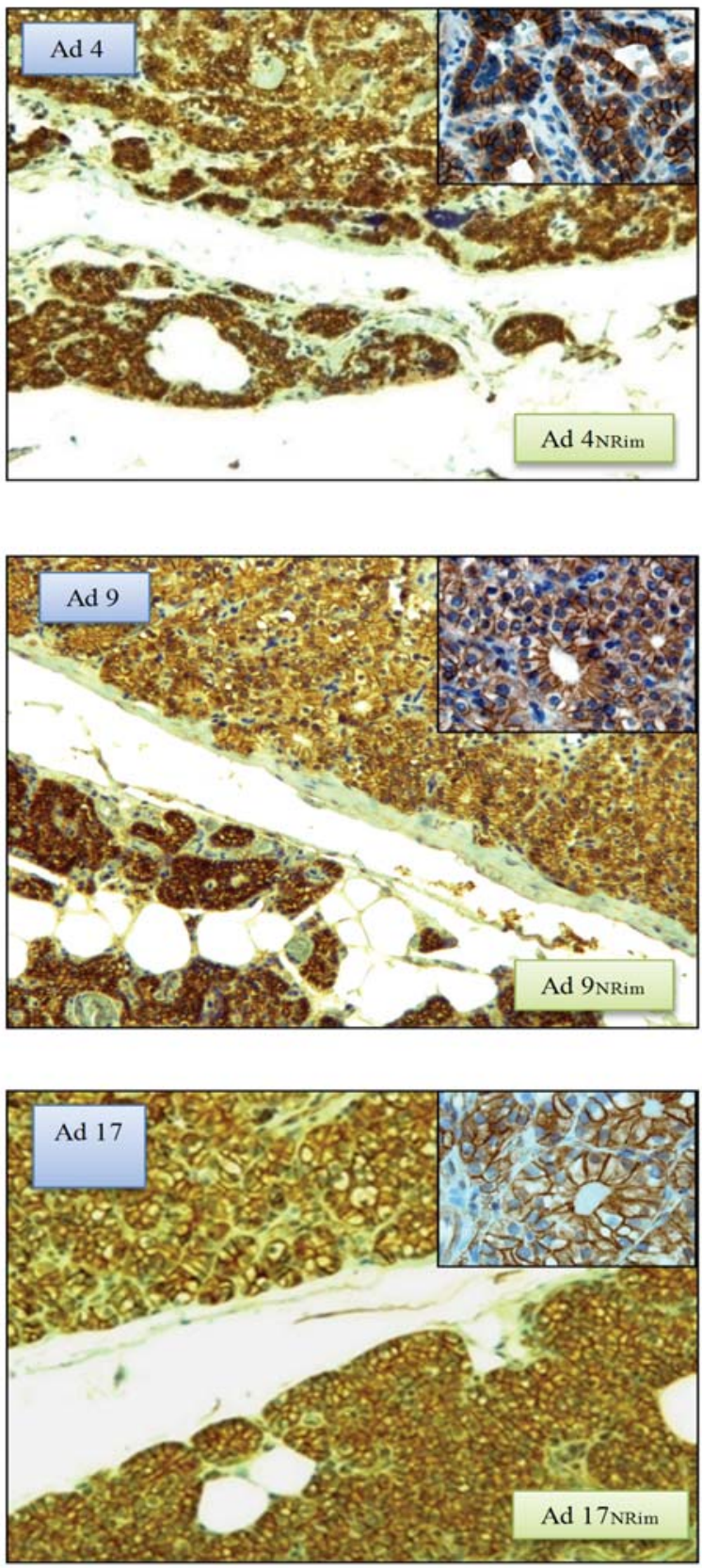

Figure 4. Photomicrographs showing immunohistochemical detection of activated B-catenin (left) and C-terminal B-catenin (right) in parathyroid adenomas (Ad 4, 9 and 17) with corresponding normal parathyroid rim ( $\mathrm{Ad}_{\mathrm{NRim}} 4,9$ and 17). Active B-catenin is detected in cytoplasm and nuclei. C-terminal $\beta$-catenin is predominantly localized to the cellular membrane and cytoplasm, as shown in larger magnification (inserts) of the adenomas.

in $1 / 18(6 \%)$ adenomas and in $4 / 12(33 \%)$ carcinoma patients, whereby no tumor nuclei stained positive.

Expression of cyclin D1 and $\beta$-catenin in parathyroid tumors and non-tumorous tissues. Cyclin D1 nuclear expression was detected in varying proportions of the tumor cells in adenomas (6-100\%) and in carcinomas (2-78\%). In 8/18 adenomas and $9 / 12$ carcinomas, the proportion of positive cells was above the range observed in the normal parathyroid rims (5-19\%, Table II). Comparing adenomas and carcinomas using the Mann-Whitney U test, no significant differences in the amount of positively stained nuclei was observed $(\mathrm{p}=0.41)$.
For ß-catenin, highly similar expression patterns were revealed in parathyroid adenomas and carcinomas, as well as in comparison to normal parathyroid rims (Fig. 4). Thus, for active B-catenin all cases demonstrated cytoplasmic staining in all cells together with a mixture of positive and negative nuclei. Pronounced immunoreactivity was observed for C-terminal $B$-catenin in the cellular membrane together with relatively weaker cytoplasmic expression of all cells. Furthermore, the expression levels in individual cells were comparable between adenomas, carcinomas and normal parathyroid rims. This finding was in agreement with Western blot analysis of non-tumorous surgical biopsies of parathyroid tissue and reference adenomas (Fig. 3D). 
Loss of APC as a potential marker for parathyroid carcinoma. Similar or overlapping patterns of expression were observed for cyclin D1 and B-catenin in non-tumorous tissues and parathyroid tumors, and loss of GSK3- $\beta$ was found in one adenoma and four carcinomas. Based on the results these molecules were therefore regarded as less suitable for diagnostic purposes. However, nine of the 12 parathyroid carcinoma cases lacked APC immunoreactivity for the $\mathrm{N}$ terminal antibody $(75 \%)$ as compared to $0 / 18(0 \%)$ of parathyroid adenomas. The difference was statistically significant $(\mathrm{p}<0.001$, Fisher's exact test). Based on these findings, the sensitivity to detect unequivocal parathyroid carcinoma based on negative APC immunoreactivity would be $75 \%$ (95\% CI, $43-95 \%$ ), whereas the specificity reaches $100 \%$ (95\% CI, $81-$ $100 \%)$. The corresponding PPV is $100 \%$, i.e. the chance that an unequivocal carcinoma is correctly identified by negative APC staining. Given the low prevalence (1\%) of parathyroid carcinoma in PHPT, the NPV is $99.7 \%$, i.e. the chance that an adenoma is correctly identified by positive APC staining.

Immunostaining with the C-terminal APC antibody also showed a statistically significant difference between unequivocal carcinomas and adenomas $(p<0.002$, Fisher's exact test). The sensitivity to distinguish unequivocal parathyroid carcinoma based on negative APC immunoreactivity using the C-terminal APC antibody was 50\% (95\% CI, $21-79 \%$ ), whereas the specificity reached $100 \%$ (95\% CI, $81-100 \%)$, and the PPV and NPV values reached $100 \%$ and $99.5 \%$, respectively.

Comparison of the N-terminal APC antibody stainings with previously published parafibromin staining of the same unequivocal cases (16) (Table III) indicated a correlation between APC and parafibromin staining findings ( $\mathrm{p}=0.48$, McNemar's $\chi^{2}$ ) which was further supported by the Cohen's Kappa test (kappa=0.56).

\section{Discussion}

In the current study we demonstrate loss of APC and GSK3- $\beta$ immunoreactivity in parathyroid carcinomas without an increase in B-catenin or cyclin D1 levels. All cases were directly fixed using formalin and have also been assessed by antibodies directed at other proteins, such as parafibromin, cyclin D1, and Ki-67. The carcinoma cases that exhibited negative APC and/or GSK3- $\beta$ expression were positive for other markers (Table III), indicating intact proteins and valid fixation processes of these samples. The observed loss of APC and GSK3- $\beta$ immunoreactivity in these cases can therefore be regarded as biological phenomenon and not due to suboptimal fixation.

APC has an established role in colorectal cancer (24), and play key roles in various fields such as cell migration, adhesion, apoptosis, chromosome segregation and neuronal differentiation (25). In this study, frequent loss of APC expression was demonstrated using two different antibodies targeting epitopes at different parts of the APC protein. The findings suggest that full-length APC and its isoforms are present in non-tumorous parathyroid and parathyroid adenomas, while the expression is specifically lost in the majority of parathyroid carcinomas. This is in agreement with a recent report demonstrating APC expression in all cases of normal parathyroid glands, parathyroid adenomas and secondary HPT (hyperplastic) glands (26).

Loss of APC immunoreactivity was observed in the majority of parathyroid unequivocal carcinomas suggesting inactivation of both alleles at this locus. Several different mechanisms could be considered as underlying these observations including gene copy number losses, structural mutations and epigenetic or other regulatory mechanisms. In parathyroid carcinomas loss of the $5 q$ region have not been frequently observed using conventional CGH analyses (27). Furthermore, loss of immunoreactivity was readily demonstrated by the N-terminal APC antibody, indicating that truncating or non-sense structural mutations of the type observed in colorectal cancer is not a major feature in parathyroid carcinoma. In sporadic colorectal cancer, the $A P C$ gene is mutated in approximately two thirds of cases. These mutations are often located within exons 5-8, 9-14, or 15, and almost invariably give rise to loss of the functionally active C-terminal region (28). Epigenetic events acting on the promoter and/or histone level, or other regulatory mechanisms acting on the transcript and/or protein level of APC remain to be studied in parathyroid carcinomas.

Interestingly, five parathyroid carcinoma cases that were negative for the $\mathrm{N}$-terminal APC antibody were positive using the C-terminal antibody (Ca 1-3, 6 and 9). Differential expression of APC isoforms, missense mutations in exon 3 and differences in antigen immunoreactivity or unspecific cross binding might explain these differences. Furthermore, two carcinomas exhibiting N-terminal APC immunoreactivity were negative using the $\mathrm{C}$-terminal antibody, suggestive of protein truncations in these tumors (Ca 11-12).

Inactivation of APC has been coupled to the familial adenomatous polyposis (FAP) syndrome, in which the affected members display early adult life colorectal cancer consequential to widespread adenomatous polyps of the colon (24). Interestingly, patients with family history of colonic polyposis and colorectal cancer have in few cases been associated to endocrine neoplasias, including parathyroid adenomas (29), as well as lesions of the jaws (30). Jaw tumors are also a feature of the HPT-JT syndrome caused by germline HRPT2 mutations, in which the afflicted members may present with PHPT that is frequently malignant, ossifying jaw tumors as well as various lesions of the kidney and uterus (31). The parathyroid carcinomas and adenomas enlisted in this study have previously been analyzed for parafibromin immunoreactivity (16). This revealed almost $100 \%$ positive cells in parathyroid adenomas and corresponding normal parathyroid rims together with reduced expression in the majority of carcinomas (Table III). Furthermore, we found a significant correlation between reduction of parafibromin and loss of APC immunoreactivity in carcinomas, suggesting a relationship between these two suppressor molecules in parathyroid tumorigenesis.

The normal function of GSK3- $\beta$ would theoretically be in agreement with a tumor suppressor function; however inactivating alterations of the GSK3- $\beta$ gene have not been reported in human cancers (32). Here we demonstrate loss of immunoreactivity of GSK3- $\beta$ in 33\% of carcinomas and in a single adenoma, supporting a role of inactivated GSK3- $\beta$ in parathyroid tumor development. 
Previous studies of $\beta$-catenin in PHPT have reported homozygous S37A mutations in exon 3 and accumulation of B-catenin for some populations $(26,33)$ but not in other $(34,35)$. In this study we observed expression of active and C-terminal B-catenin in surgical biopsies of non-tumorous parathyroid by Western, as well as in normal parathyroid rim. Active $\beta$-catenin revealed similar expression patterns in cytoplasm and nucleus of normal rim, adenomas and carcinomas. Furthermore, no difference in $B$-catenin expression was revealed between carcinomas with positive or negative APC or GSK3- $\beta$ staining. Neither were there any associations between $B$-catenin expression and cyclin D1 expression in carcinomas with partial loss of parafibromin. These findings would suggest that parathyroid related S37A mutation was not frequent in this tumor series since the $8 \mathrm{E} 7$ antibody applied is not reactive to this form (10). Given the low rate of cell division of the normal parathyroid gland, the high levels of active $\beta$-catenin observed in non-tumorous parathyroid cells are not expected to stimulate proliferation. Indeed, several in vivo studies indicate that $B$-catenin and the Wnt pathway could mediate apoptosis and differentiation in addition to proliferation (36). Furthermore, loss of APC and GSK3- 3 might confer a proliferative stimulus to parathyroid tumors independent of $\beta$-catenin. APC has several functions in the cell in addition to the control of $\beta$-catenin turn-over, such as regulation of apoptosis, cell-cell adhesion and inhibition of genomic replication by direct binding to the DNA $(25,37)$. Furthermore, GSK3- $\beta$ is for example involved in suppression of the oncogene cyclin D2 and stimulation of MEKK1 expression, a member of the JNK/SAPK cascade elicited in cellular stress $(38,39)$.

In this tumor series, APC immunohistochemistry was found as a potentially useful tool for improved diagnostic purposes. Parafibromin alterations are commonly detected as loss of immunoreactivity in a subset of cells only ("partial loss'), and varying patterns of staining of non-tumorous parathyroid and adenomas have been found in different studies (13-17). By contrast, APC showed uniform loss in carcinomas together with almost $100 \%$ positive cells in normal rim and adenomas. Thus two of the molecules studied in this sample series (APC and parafibromin) showed clear expression in all cells of sall non-tumorous parathyroid and parathyroid adenoma, but were lost in the majority of parathyroid carcinomas. Similarly, proliferation index determined by Ki-67 (antibody MIB1) which is generally low in normal parathyroid and parathyroid adenoma (20) and increased in carcinomas $(21,40)$ was found elevated (range $3.3-7.8 \%$ ) in $6 / 12$ carcinomas studied (Table III). Taken together, these three markers could constitute a useful panel in assessing malignant parathyroid tumors. Although based on a limited number of cases, all carcinomas studied here would be distinguished from parathyroid adenoma using this approach.

If substantiated in independent material, loss of APC expression imply an appealing possibility for oncological intervention in patients with parathyroid carcinoma. For example, COX-2 inhibitors have been shown to exhibit chemopreventive features in colorectal cancer, as treatment with non-steroidal anti-inflammatory drugs (NSAID) have shown a reduction of polyp size and numbers in FAP patients (41). Similarly, treatment with aspirin has also been shown to reduce the incidence and mortality of colorectal cancer (42). It has been shown recently that truncated APC still can target $B$-catenin for destruction, but only in the absence of COX enzyme activity, providing a possible molecular explanation for the promising results of COX-2 inhibition in colorectal cancer (43). Although our data need to be reproduced on a genetic level to verify the mechanisms of APC abolishment in parathyroid cancer, these possibilities for therapeutic intervention in parathyroid carcinoma and disease prevention in familial disease are truly intriguing.

To conclude, our study is the first that connects loss of APC and GSK3-B immunoreactivity to parathyroid malignancy without an ensuing augmentation in active $\beta$-catenin or cyclin D1 levels. APC constitute a promising novel marker for the detection of parathyroid cancer with statistical confidence, and all cancer cases in the current study were distinguished using the panel APC-parafibromin-Ki-67. This report also brings new insight into the complex molecular biology of parathyroid tumors, in which we report the hypothesized inactivation of a colorectal cancer tumor suppressor in the majority of malignant parathyroid cases as well as its coupling to a reduction in parafibromin levels. Furthermore, on a purely speculative level, loss of APC expression in parathyroid cancer might confer new therapeutic opportunities for the clinician.

\section{Acknowledgements}

The authors are indebted to Mrs. Anita Salomon, Oraphan Kaewmanee, Mai Trinh and Lisa Ånfalk for excellent technical assistance, to Mrs. Elisabeth Berg and Dr Janos Geli for statistical analyses. The study was financially supported by The Swedish Cancer Foundation, The Cancer Society in Stockholm, The Gustav V Jubilee Foundation, The Göran Gustavsson Foundation for Research in Natural Sciences and Medicine, The Swedish Research Council, Stockholm County Council and Karolinska Institutet.

\section{References}

1. Carpten JD, Robbins CM, Villablanca A, Forsberg L, Presciuttini S, Bailey-Wilson J, Simonds WF, Gillanders EM, Kennedy AM, Chen JD, Agarwal SK, Sood R, Jones MP, Moses TY, Haven C, Petillo D, Leotlela PD, Harding B, Cameron D, Pannett AA, Höög A, Heath H III, James-Newton LA, Robinson B, Zarbo RJ, Cavaco BM, Wassif W, Perrier ND, Rosen IB, Kristoffersson U, Turnpenny PD, Farnebo LO, Besser GM, Jackson CE, Morreau H, Trent JM, Thakker RV, Marx SJ, Teh BT, Larsson C and Hobbs MR: HRPT2, encoding parafibromin, is mutated in hyperparathyroidismjaw tumor syndrome. Nat Genet 32: 676-680, 2002.

2. Howell VM, Haven CJ, Kahnoski K, Khoo SK, Petillo D, Chen J, Fleuren GJ, Robinson BG, Delbridge LW, Philips J, Nelson AE, Krause U, Hammje K, Dralle H, Hoang-Vu C, Gimm O, Marsh DJ, Morreau $\mathrm{H}$ and Teh BT: HRPT2 mutations are associated with malignancy in sporadic parathyroid tumours. J Med Genet 40: 657-663, 2003 .

3. Shattuck TM, Välimäki S, Obara T, Gaz RD, Clark OH, Shoback D, Wierman ME, Tojo K, Robbins CM, Carpten JD, Farnebo LO, Larsson C and Arnold A: Somatic and germ-line mutations of the HRPT2 gene in sporadic parathyroid carcinoma. N Engl J Med 349: 1722-1729, 2003.

4. Cetani F, Pardi E, Borsari S, Viacava P, Dipollina G, Cianferotti L, Ambrogini E, Gazzerro E, Colussi G, Berti P, Miccoli P, Pinchera A and Marcocci C: Genetic analyses of the HRPT2 gene in primary hyperparathyroidism: germline and somatic mutations in familial and sporadic parathyroid tumors. J Clin Endocrinol Metab 89: 5583-5591, 2004. 
5. Krebs LJ, Shattuck TM and Arnold A: HRPT2 mutational analysis of typical sporadic parathyroid adenomas. J Clin Endocrinol Metab 90: 5015-5057, 2005.

6. Juhlin C, Höög A, Yakoleva T, Leibiger I, Leibiger B, Weber G, Larsson $C$ and Villablanca A: Loss of parafibromin expression in a subset of sporadic parathyroid adenomas. Endocr Relat Cancer 13: 509-523, 2006.

7. Mosimann C, Hausmann G and Basler K: Parafibromin/Hyrax activates $\mathrm{Wnt} / \mathrm{Wg}$ target gene transcription by direct association with B-catenin/Armadillo. Cell 125: 327-341, 2006.

8. Rubinfeld B, Souza B, Albert I, Muller O, Chamberlain SH, Masiarz FR, Munemits S and Polakis P: Association of the APC gene product with $ß$-catenin. Science 262: 1731-1734, 1993.

9. Su LK, Vogelstein B and Kinzler KW: Association of the APC tumor suppressor protein with catenins. Science 262: 1734-1737, 1993.

10. Van Noort M, Meeldijk J, van der Zee R, Destree O and Clevers H: Wnt signaling controls the phosphorylation status of beta-catenin J Biol Chem 277: 17901-17905, 2002.

11. Shane E: Clinical review 122: parathyroid carcinoma. J Clin Endocrinol Metab 86: 485-493, 2001

12. Rodgers SE and Perrier ND: Parathyroid carcinoma. Curr Opin Oncol 18: 16-22, 2006.

13. Tan MH, Morrison C, Wang P, Yang X, Haven CJ, Zhang C, Zhao P, Tretiakova MS, Korpi-Hyovalti E, Burgess JR, Soo KC, Cheah WK, Cao B, Resau J, Morreau H and Teh BT: Loss of parafibromin immunoreactivity is a distinguishing feature of parathyroid carcinoma. Clin Cancer Res 10: 6629-6637, 2004.

14. Gill AJ, Clarkson A, Gimm O, Keil J, Dralle H, Howell VM and Marsh DJ: Loss of nuclear expression of parafibromin distinguishes parathyroid carcinomas and hyperparathyroidism-jaw tumor (HPT-JT) syndrome-related adenomas from sporadic parathyroid adenomas and hyperplasias. Am J Surg Pathol 30: 1140-1149, 2006.

15. Cetani F, Ambrogini E, Viacava P, Pardi E, Fanelli G, Naccarato AG, Borsari S, Lemmi M, Berti P, Miccoli P, Pinchera A and Marcocci C: Should parafibromin staining replace HRPT2 gene analysis as an additional tool for histologic diagnosis of parathyroid carcinoma? Eur J Endocrinol 156: 547-554, 2007

16. Juhlin CC, Villablanca A, Sandelin K, Haglund F, Nordenström J, Forsberg L, Bränström R, Obara T, Arnold A, Larsson C and Höög A: Parafibromin immunoreactivity - its use as an additional diagnostic marker for parathyroid tumor classification. Endocr Relat Cancer 14: 501-512, 2007

17. Shamlal M and DeLellis RA: In response. Adv Anat Pathol 15: 179-180, 2008.

18. Tominaga Y, Tsuzuki T, Matsuoka S, Uno N, Sato T, Shimabukuro S, Goto N, Nagasaka T and Uchida K: Expression of parafibromin in distant metastatic parathyroid tumors in patients with advanced secondary hyperparathyroidism due to chronic kidney disease. World J Surg 32: 815-821, 2008.

19. Bondeson L, Sandelin K and Grimelius L: Histopathological variables and DNA cytometry in parathyroid carcinoma. Am J Surg Pathol 17: 820-829, 1993.

20. Farnebo F, Auer G, Farnebo L-O, Teh BT, Twigg S, Aspenbladh U, Thompson NW, Grimelius L, Larsson C and Sandelin K: Evaluation of retinoblastoma and Ki-67 as diagnostic markers in benign and malignant parathyroid disease. World J Surg 23: 68-74, 1999

21. DeLellis RA, Lloyd RV, Heitz PU and Eng C: Pathology and genetics of the tumours of endocrine organs. In: WHO Classification of Tumours. DeLellis RA, Lloyd RV, Heitz PU and Eng C (eds). IARC Press, Lyon, pp124-127, 2006.

22. Lu M, Forsberg L, Höög A, Juhlin CC, Vukojevic V, Larsson C, Conigrave AD, Delbridge LW, Gill A, Bark C, Farnebo LO and Bränström R: Heterogeneous expression of SNARE proteins SNAP-23, SNAP-25, Syntaxin1 and VAMP in human parathyroid tissue. Mol Cell Endocrinol 287: 72-80, 2008.

23. Kraus C, Reina-Sanchez J, Suleková $Z$ and Ballhausen WG: Immunochemical identification of novel high-molecular-weight protein isoforms of the adenomatous polyposis coli (APC) gene. Int J Cancer 65: 383-388, 1996.
24. Groden J, Thliveris A, Samowitz W, Carlson M, Gelbert L, Albertsen H, Joslyn G, Stevens J, Spirio L and Robertson M: Identification and characterization of the familial adenomatous polyposis coli gene. Cell 66: 589-600, 1991.

25. Hanson CA and Miller JR: Non-traditional roles for the adenomatous polyposis coli (APC) tumor suppressor protein. Gene 361: 1-12, 2005.

26. Björklund P, Àkerström G and Westin G: Accumulation of nonphosphorylated $B$-catenin and $\mathrm{c}$-myc in primary and uremic secondary hyperparathyroid tumors. J Clin Endocrinol Metab 92: 338-344, 2007.

27. Kytölä S, Farnebo F, Obara T, Isola J, Grimelius L, Farnebo L-O, Sandelin K and Larsson C: Patterns of chromosomal imbalances in parathyroid carcinomas. Am J Pathol 157: 579-586, 2000.

28. Segditsas S and Tomlinson I: Colorectal cancer and genetic alterations in the Wnt pathway. Oncogene 25: 7531-7537, 2006.

29. Schneider NR, Cubilla AL and Chaganti RS: Association of endocrine neoplasia with multiple polyposis of the colon. Cancer 51: 1171-1175, 1983.

30. Offerhaus GJ, Levin LS, Giardiello FM, Krush AJ, Welsch SB, Booker SV, Hasler JF, McKusick VA, Yardley JH and Hamilton SR: Occult radiopaque jaw lesions in familial adenomatous polyposis coli and hereditary nonpolyposis colorectal cancer. Gastroenterology 93: 490-947, 1987.

31. Jackson CE, Norum RA, Boyd SB, Talpos GB, Wilson SD, Taggart RT and Mallette LE: Hereditary hyperparathyroidism and multiple ossifying jaw fibromas: a clinically and genetically distinct syndrome. Surgery 108: 1006-1012, 1990.

32. Karim R, Tse G, Putti T, Scolyer R and Lee S: The significance of the Wnt pathway in the pathology of human cancers. Pathology 36: 120-128, 2004.

33. Björklund P, Lindberg D, Åkerström G and Westin G: Stabilizing mutation of CTNNB1/beta-catenin and protein accumulation analyzed in a large series of parathyroid tumors of Swedish patients. Mol Cancer 7: 53, 2008.

34. Ikeda S, Ishizaki Y, Shimizu Y, Fujimori M, Ojima Y, Okajima M, Sugino K and Asahara T: Immunohistochemistry of cyclin D1 and beta-catenin, and mutational analysis of exon 3 of beta-catenin gene in parathyroid adenomas. Int J Oncol 20: 463-466, 2002.

35. Costa-Guda J and Arnold A: Absence of stabilizing mutations of beta-catenin encoded by CTNNB 1 exon 3 in a large series of sporadic parathyroid adenomas. J Clin Endocrinol Metab 92: 1564-1566, 2007.

36. Bordonaro M, Lazarova DL and Sartorelli AC: Hyperinduction of Wnt activity: a new paradigm for the treatment of colorectal cancer? Oncol Res 17: 1-9, 2008.

37. Qian J, Sarnaik AA, Bonney TM, Keirsey J, Combs KA, Steigerwald K, Acharya S, Behbehani GK, Barton MC, Lowy AM and Groden J: The APC tumor suppressor inhibits DNA replication by directly binding to DNA via its carboxyl terminus. Gastroenterology 135: 152-162, 2008.

38. Kim JW, Lee JE, Kim MJ, Cho EG, Cho SG and Choi EJ: Glycogen synthase kinase 3 beta is a natural activator of mitogenactivated protein kinase/extracellular signal-regulated kinase kinase kinase 1 (MEKK1). J Biol Chem 278: 13995-14001, 2003.

39. Huang W, Chang HY, Fei T, Wu H and Chen YG: GSK3 beta mediates suppression of cyclin D2 expression by tumor suppressor PTEN. Oncogene 26: 2471-2482, 2007.

40. Iihara M, Okamoto T, Suzuki R, Kawamata A, Nishikawa T, Kobayashi M and Obara T: Functional parathyroid carcinoma: long-term treatment outcome and risk factor analysis. Surgery 142: 936-943, 2007.

41. Giardiello FM, Hamilton SR, Krush AJ, Booker S, Jen J, Giardiello FM, Hamilton SR, Vogelstein B and Kinzler KW: Treatment of colonic and rectal adenomas with sulindac in familial adenomatous polyposis. N Engl J Med 328: 1313-1316, 1993.

42. Thun MJ, Namboodiri MM and Heath CW Jr: Aspirin use and reduced risk of fatal colon cancer. N Engl J Med 325: 1593-1596, 1991 .

43. Eisinger AL, Nadauld LD, Shelton DN, Prescott SM, Stafforini DM and Jones DA: Retinoic acid inhibits B-catenin through suppression of cox-2: a role for truncated adenomatous polyposis coli. J Biol Chem 282: 29394-29400, 2007. 